\title{
Manometric and pH-monitoring changes after laparoscopic sleeve gastrectomy: a systematic review
}

\author{
Andrea Balla ${ }^{1}$ (D ) Francesca Meoli ${ }^{1} \cdot$ Livia Palmieri ${ }^{1} \cdot$ Diletta Corallino $^{1} \cdot$ Maria Carlotta Sacchi $^{2} \cdot$ Emanuela Ribichini $^{2}$. \\ Diego Coletta ${ }^{3} \cdot$ Annamaria Pronio $^{4} \cdot$ Danilo Badiali $^{2} \cdot$ Alessandro M. Paganini $^{1}$
}

Received: 30 January 2021 / Accepted: 5 April 2021 / Published online: 14 April 2021

(C) The Author(s) 2021

\begin{abstract}
Purpose Aim of this systematic review is to assess the changes in esophageal motility and acid exposure of the esophagus through esophageal manometry and 24-hours pH-monitoring before and after laparoscopic sleeve gastrectomy (LSG).

Methods Articles in which all patients included underwent manometry and/or 24-hours pH-metry or both, before and after LSG, were included. The search was carried out in the PubMed, Embase, Cochrane, and Web of Science databases, revealing overall 13,769 articles. Of these, 9702 were eliminated because they have been found more than once between the searches. Of the remaining 4067 articles, further 4030 were excluded after screening the title and abstract because they did not meet the inclusion criteria. Thirty-seven articles were fully analyzed, and of these, 21 further articles were excluded, finally including 16 articles. Results Fourteen and twelve studies reported manometric and pH-metric data from 402 and 547 patients, respectively. At manometry, a decrease of the lower esophageal sphincter resting pressure after surgery was observed in six articles. At 24hours pH-metry, a worsening of the DeMeester score and/or of the acid exposure time was observed in nine articles and the de novo gastroesophageal reflux disease (GERD) rate that ranged between 17.8 and $69 \%$. A meta-analysis was not performed due to the heterogeneity of data.

Conclusions After LSG a worsening of GERD evaluated by instrumental exams was observed such as high prevalence of de novo GERD. However, to understand the clinical impact of LSG and the burden of GERD over time further long-term studies are necessary.
\end{abstract}

Keywords Gastroesophageal reflux disease (GERD) $\cdot$ Sleeve gastrectomy $\cdot$ Manometry $\cdot$ pH-metry $\cdot 24 h$-pH-impedance

Andrea Balla

andrea.balla@gmail.com

1 Bariatric Surgery Unit, Department of General Surgery and Surgical Specialties "Paride Stefanini”, Sapienza University of Rome, Azienda Policlinico Umberto I, Viale del Policlinico 155, 00161 Rome, Italy

2 Department of Translational and Precision Medicine, Sapienza University of Rome, Azienda Policlinico Umberto I, Viale del Policlinico 155, 00161 Rome, Italy

3 Department of General Surgery, Emergency Department, Emergency and Trauma Surgery Unit, Sapienza University of Rome, Azienda Policlinico Umberto I, Viale del Policlinico 155, 00161 Rome, Italy

4 Digestive Endoscopy Unit, Department of General Surgery and Surgical Specialties "Paride Stefanini", Sapienza University of Rome, Azienda Policlinico Umberto I, Viale del Policlinico 155, 00161 Rome, Italy

\section{Introduction}

Laparoscopic sleeve gastrectomy (LSG) is presently considered a safe, easy, and effective stand-alone procedure for the treatment of morbid obesity, in terms of weight loss and comorbidity resolution and with low morbidity [1-5]. For these reasons, LSG quickly gained widespread popularity both in the USA and in Europe [5-8].

In obese patients with proven gastroesophageal reflux disease (GERD), the bariatric surgical treatment of choice is laparoscopic Roux-en-Y gastric bypass (LRYGB) due to its excellent results in terms of GERD resolution [9-11], but the outcomes of GERD after LSG are still debated [2-5]. Most published articles analyzing GERD after LSG investigate symptoms [1, 12], but several obese patients have few or no GERD symptoms, and often there is no agreement between the presence of symptoms and the diagnostic assessment findings $[5,8,13]$. For this reason, the introduction of endoscopy, 
manometry, and 24-hours pH-monitoring in the routine preand postoperative workup of patients candidate to bariatric surgery could change the management strategy in these patients $[1-3,5,8,13]$. The detection of GERD by instrumental assessment in asymptomatic patients before surgery could switch the indication from LSG to LRYGB, while the postoperative diagnosis of severe GERD, albeit asymptomatic, could set the indication for re-do surgery from LSG to LRYGB, in order to prevent the occurrence of Barrett's esophagus [1-3, 5, $8,13]$.

Another debated issue about GERD in bariatric surgery is the presence of hiatal hernia $[2,3,10,12,13]$. Some authors reported an improvement in GERD symptoms when hiatal hernia is diagnosed and repaired, even if these data are not confirmed by others $[2,3,10,12,13]$.

The aim of this systematic review is to assess the changes in esophageal motility and acid exposure of the esophagus through esophageal manometry and 24-hours $\mathrm{pH}$-monitoring, before and after LSG.

\section{Materials and methods}

Institutional review board approval and informed consent from participants were not needed for this systematic review.

\section{Inclusion criteria}

Inclusion criteria were (1) articles from any country written in English, Spanish, or Italian and (2) articles in which all included patients underwent manometry and/or 24-hours pH-metry or both, before and after LSG.

\section{Exclusion criteria}

Exclusion criteria were (1) assessment of gastroesophageal reflux only by patients' reporting of symptoms and/or endoscopy; (2) bariatric surgical techniques different from LSG; (3) gastroesophageal reflux assessment performed only in selected patients; (4) evaluation by manometry or $\mathrm{pH}$-metry performed only before or only after LSG; (5) presence of associated procedures (omentopexy); (6) reviews, systematic reviews, meta-analysis, studies with data retrieved from registries, comments, case reports, correspondence and letters to editor, editorials, technical surgical notes, and imaging studies; and (7) animals involvement.

\section{Search strategy}

We conducted a systematic review of published articles according to the preferred reporting items for systematic review and meta-analysis (PRISMA) statement [14]. The search was carried out in the PubMed, Embase, Cochrane, and Web of
Science databases [15] using the keywords reported in Table 1.

Overall, the search revealed 13769 articles published until November 2019. Of these, 9702 were eliminated because they were found more than once. Of the remaining 4067 articles, further 4030 were excluded after screening title and abstract because they did not meet the inclusion criteria.

\section{Quality assessment of included articles}

Two authors (A.B. and F.M.) assessed the quality of the included papers by a modified Newcastle-Ottawa Scale (NOS) for cohort studies [16]. NOS is based on three factors for the evaluation of each paper: patients' selection, comparability, and the completeness of the reported results (postoperative outcomes) [16]. The maximum score attributable to each article is nine points [16].

\section{Risk of bias assessment of included articles}

Two authors (A.B. and F.M.) assessed the risk of bias of the included articles by the Risk Of Bias In Non-randomized Studies of Interventions (ROBIN-I) tool [17]. ROBIN-I includes seven domains: the first two domains concern confounding and selection of participants into the study, the third domain addresses classification of the interventions, and the last four domains address biases due to deviations from intended interventions, missing data, outcomes measurement, and selection of the reported result [17]. Based on judgments

Table 1 Keywords used for research in the PubMed, Embase, Cochrane, and Web of Science databases

sleeve gastrectomy AND ph manometry

sleeve gastrectomy AND ph-manometry

bariatric surgery AND ph manometry

bariatric surgery AND ph-manometry

sleeve gastrectomy AND manometry

bariatric surgery AND manometry

sleeve gastrectomy AND reflux

bariatric surgery AND reflux

sleeve gastrectomy AND GERD

bariatric surgery AND GERD

sleeve gastrectomy AND 24h-pH-impedance

sleeve gastrectomy AND 24h pH impedance

sleeve gastrectomy AND pH-impedance

sleeve gastrectomy AND $\mathrm{pH}$ impedance

bariatric surgery AND 24h-pH-impedance

bariatric surgery AND 24h pH impedance

bariatric surgery AND $\mathrm{pH}$-impedance

bariatric surgery AND pH impedance 
assigned for each domain, at the end, one single judgment is assigned to the entire article [17].

\section{Study design}

After screening the title and abstract, the articles that fulfilled the inclusion criteria were identified, and their full text was reviewed. Data were extracted and stored in the Microsoft Excel program (Microsoft Corporation, Redmond, Washington, USA).

The following data were extracted from each article: authors, year of publication, type of study, number of patients, gender, age, presence of hiatal hernia, bougie size, distance of gastrectomy from pylorus, if oversewing was performed, preand postoperative body mass index (BMI), manometry or 24hours $\mathrm{pH}$-metry technique employed, manometric and $\mathrm{pH}$ metric data, symptoms, and timing of postoperative manometric, $\mathrm{pH}$-metric, and symptom evaluation.

\section{Results}

Thirty-seven articles were fully analyzed, and 21 further articles were excluded. Finally, 16 articles published between February 2013 and September 2019 were included [18-33], as shown in the PRISMA flow diagram (Fig. 1) [14]. The assessments of quality based on NOS and of the risk of bias based on ROBIN-I of the included articles are shown in Tables 2 and 3.

Manometric and pH-metric data were obtained from 402 and 547 patients, respectively [18-33]. Hiatal hernia was diagnosed preoperatively in 32 patients [19, 21, 23, 26, 29, 32], and in four cases it was repaired. In one patient by cruroplasty, even if it was not specified whether anterior or posterior [21], and in the other three cases, the type of hiatal repair was not specified [32] (Table 4). Overall, 29 hiatal hernias were diagnosed postoperatively. A bougie size of $36 \mathrm{French}(\mathrm{Fr})$ was used in eight studies (417 patients) [19, 21-23, 25, 26, 32, 33], a bougie of $32 \mathrm{Fr}$ was used in two studies (93 patients) [18, 20], a bougie of $34 \mathrm{Fr}$ was used in two studies (43 patients) $[24,29]$, a bougie of $38 \mathrm{Fr}$ was used in two studies (38 patients) $[28,30]$, a bougie of $40 \mathrm{Fr}$ was used in only one study (25 patients) [27], and in another study the bougie size used was not reported (53 patients) (Table 4) [31]. Oversewing of the staple line was performed in four studies (132 patients) $[18-20,27]$. Distance of gastrectomy from the pylorus ranged between 2 and $6 \mathrm{~cm}$ (Table 4) [18-33]. The mean preoperative and postoperative BMI ranged between 38.8 and $48.97 \mathrm{~kg} / \mathrm{m}^{2}$ and 28.2 and $40.7 \mathrm{~kg} / \mathrm{m}^{2}$, respectively, but postoperative BMI was reported only in eight studies [18-33].

\section{Esophageal manometry}

Fourteen articles out of 16 assessed esophageal motility prior to and after LSG analyzing the lower esophageal sphincter (LES) characteristics and esophageal body peristalsis [18-31]. Conventional manometry was performed in eight studies, [18-25], while in another four studies data were obtained from high-resolution manometry (HRM) [26-29]. Results from these studies are very heterogeneous: use of different techniques, such as conventional manometry or HRM, different parameters analyzed, and variable postoperative manometry timing ranging from 1 to 12 months after surgery [18-31]. Two studies did not report manometric data because
Fig. 1 Preferred reporting items for systematic review and metaanalysis (PRISMA) flow diagram [14]. SG: sleeve gastrectomy

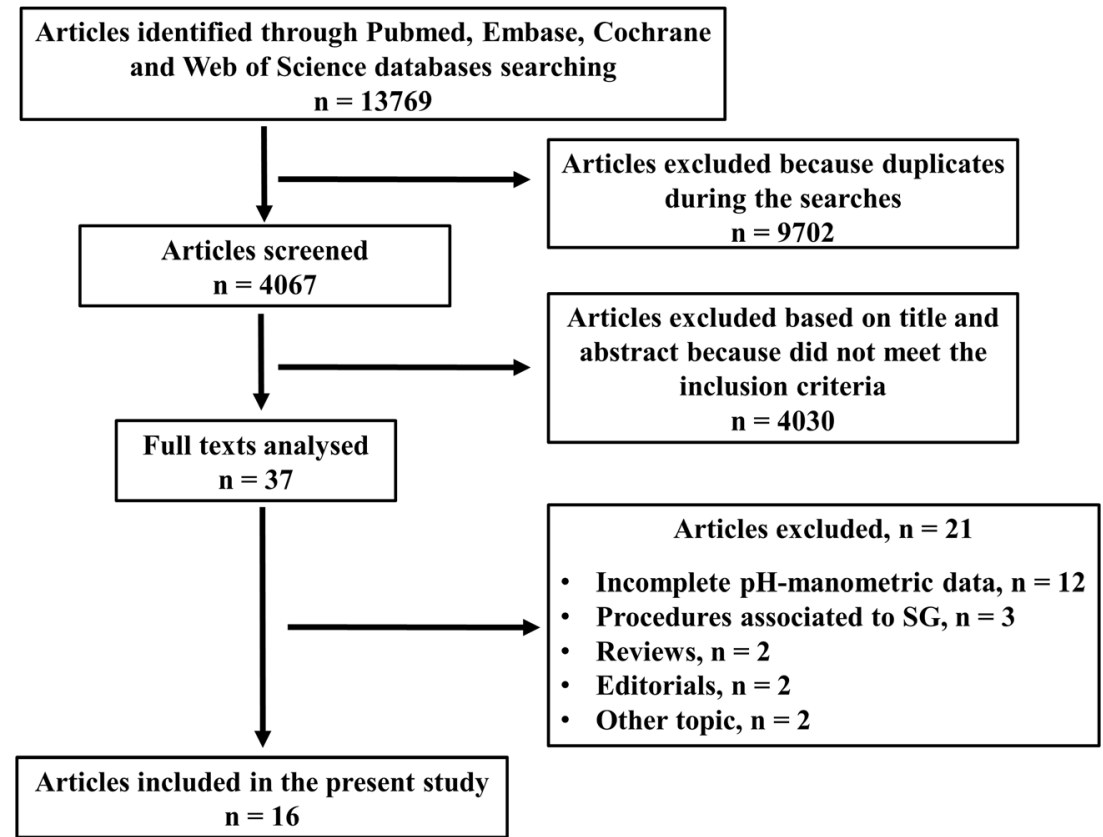


Table 2 Assessment of the articles quality based on the Newcastle-Ottawa scale (NOS) [16]

\begin{tabular}{|c|c|c|c|c|c|}
\hline Author, year, type of study & Selection & Comparability & Outcomes & $\begin{array}{l}\text { Total } \\
\text { Score }\end{array}$ & Assessment \\
\hline & 1234 & 5 & 678 & & \\
\hline Braghetto, 2010, prospective [18] & - - ** & -- & $*_{-} *$ & 4 & Poor \\
\hline Gorodner, 2015, prospective [19] & $* *_{-} *$ & -- & $*_{*}$ & 5 & Poor \\
\hline Valezi, 2017, prospective [20] & $* * * *$ & $*_{-}$ & $* * *$ & 8 & Good \\
\hline De Angulo, 2019, prospective [21] & $* *_{-} *$ & -- & $* * *$ & 6 & Poor \\
\hline Sioka, 2017, prospective [22] & $* *_{-} *$ & -- & $* * *$ & 6 & Poor \\
\hline Rebecchi, 2014, prospective [23] & $* *_{-} *$ & -- & $* * *$ & 6 & Poor \\
\hline Kleidi, 2013, prospective [24] & $* *_{-} *$ & -- & $*_{-} *$ & 5 & Poor \\
\hline Gemici, 2020, retrospective [25] & $*_{-} * *$ & -- & $*_{-} *$ & 5 & Poor \\
\hline Coupaye, 2018, prospective [26] & $--* *$ & -- & $* * *$ & 5 & Poor \\
\hline Del Genio 2014, prospective [27] & $* *_{-} *$ & -- & $* * *$ & 6 & Poor \\
\hline Tolone, 2020, prospective [28] & $*_{-} * *$ & $-*$ & $* * *$ & 7 & Fair \\
\hline Burgerhart, 2014, prospective [29] & $*_{-} * *$ & -- & $*_{-} *$ & 5 & Poor \\
\hline Georgia, 2017, prospective [30] & $* *_{-} *$ & -- & $* * *$ & 6 & Poor \\
\hline $\begin{array}{l}\text { Świdnicka-Siergiejko, } \\
\text { 2018, prospective [31] }\end{array}$ & $* *_{-} *$ & -- & $* * *$ & 6 & Poor \\
\hline Thereaux, 2016, prospective [32] & $* * * *$ & $* *$ & $*_{-} *$ & 8 & Good \\
\hline Yormaz, 2017, retrospective [33] & $* * * *$ & $* *$ & $* * *$ & 9 & Good \\
\hline
\end{tabular}

manometry was used only to rule out major motility disorders or to identify the position of the LES $[30,31]$. The remaining 12 studies assessed LES characteristics and esophageal body peristalsis [18-29] (Table 5).

\section{Conventional manometry}

Braghetto et al. collected data from twenty obese patients who underwent conventional manometry before and 6 months after LSG [18]. Data analysis was limited to the LES resting pressure and sphincter length [18]. After surgery, LES pressure significantly decreased from $14.2 \pm 5.8 \mathrm{mmHg}$ to $10.5 \pm$ $6.06 \mathrm{mmHg}(p=0.01) ; 17$ patients $(85 \%)$ presented de novo hypotensive LES, defined as resting pressure $<12.1 \mathrm{mmHg}$ [18]. Also, the length of LES was affected; prior to surgery, a total LES length of greater than $3.5 \mathrm{~cm}$ was measured in all twenty patients, as compared with only six patients after surgery [18]. Abdominal LES length was less than $1 \mathrm{~cm}$ in 14 patients [18].

Another prospective study showed similar LES changes 1 year after surgery [19]. LES resting pressure decreased in 14 patients from 17.1 to $12.4 \mathrm{mmHg}$ ( $p \leq 0.05$ ), and a hypotensive LES was detected in about $30 \%$ of patients as compared to $7 \%$ of patients preoperatively [19]. One patient developed ineffective esophageal motility 1 year after surgery, but the changes in the parameters evaluating esophageal body motility were not statistically significantly different after surgery [19].

Valezi et al. also observed changes in both esophageal body motility and LES pressure 1 year after surgery in a series of 73 patients [20]. Comparing pre- and postoperative findings, after surgery there was a statistically significant reduction in LES pressure, wave amplitude, and percentage of patients with normal peristalsis [20].

Another prospective study reported changes in esophageal body contractions in 26 patients [21]. Significant decrease of contraction amplitude in the distal esophagus was detected one year after surgery $(p=0.025)$, even if the values remained in a normal range [21]. A similar result was found in LES pressure that decreased significantly, whereas the mean value remained within the normal range [21].

In a series of 18 patients, Sioka et al. observed that patients with normal peristalsis significantly increased from 47 to $82 \%$ after a median time interval of 7 months after surgery [22]. In terms of contraction amplitude, however, the value at the upper border of the LES decreased significantly, but each contraction amplitude value remained within the normal range [22]. Finally, the manometric outcomes of LES did not change significantly [22].

Rebecchi et al. did not find any difference in LES resting pressure and distal esophageal wave amplitude in 65 patients 2 years after surgery [23].

Earlier functional evaluation from 6 weeks to 3 months after surgery was reported by two studies [24, 25]. Kleidi et al. carried out an early evaluation with functional test preoperatively and at least 6 weeks after surgery [24]. Data analysis from 23 patients showed a statistically significant increase of total and abdominal LES length [24]. The contraction amplitude in the lower esophagus decreased and there was an increase in reflux symptoms postoperatively [24]. Another 


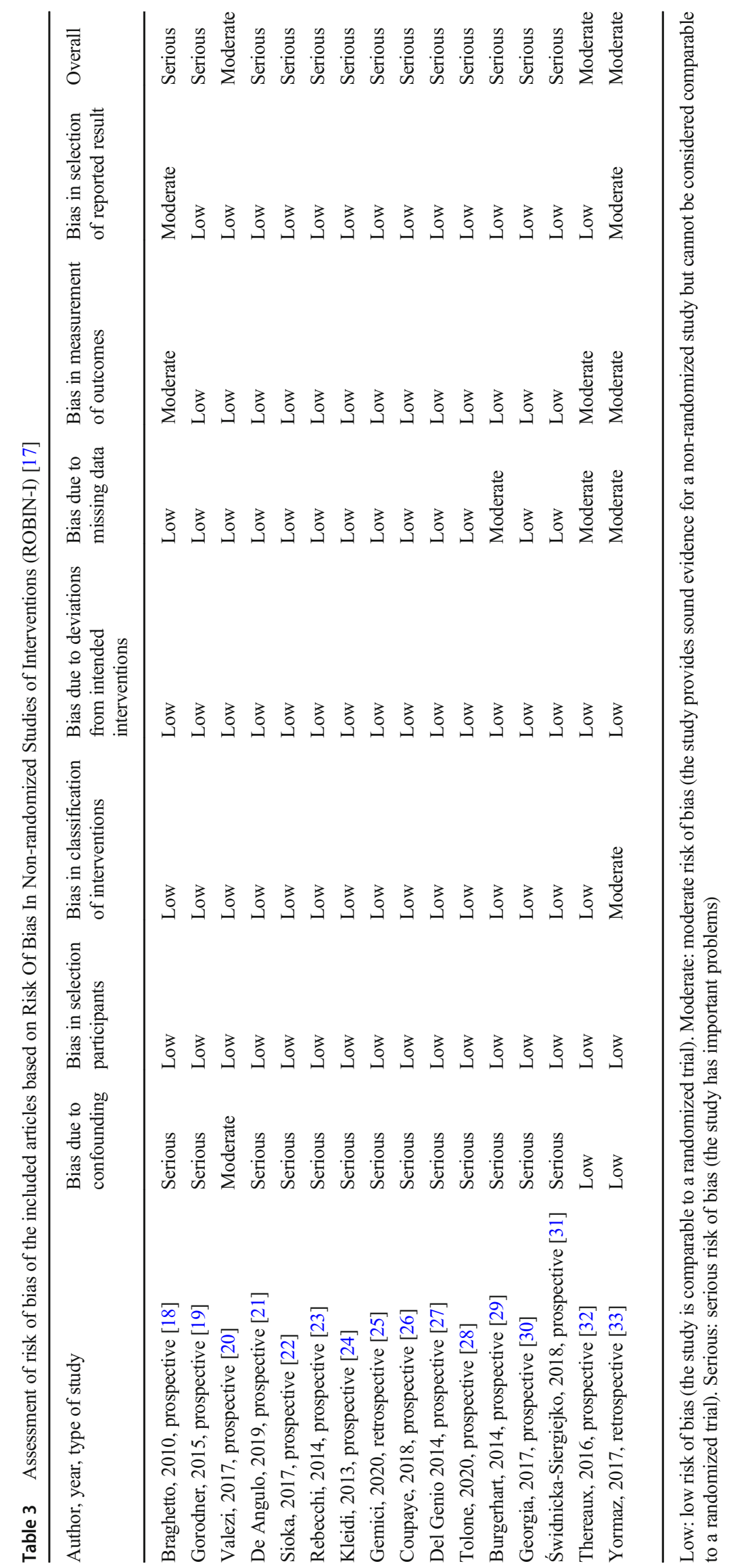




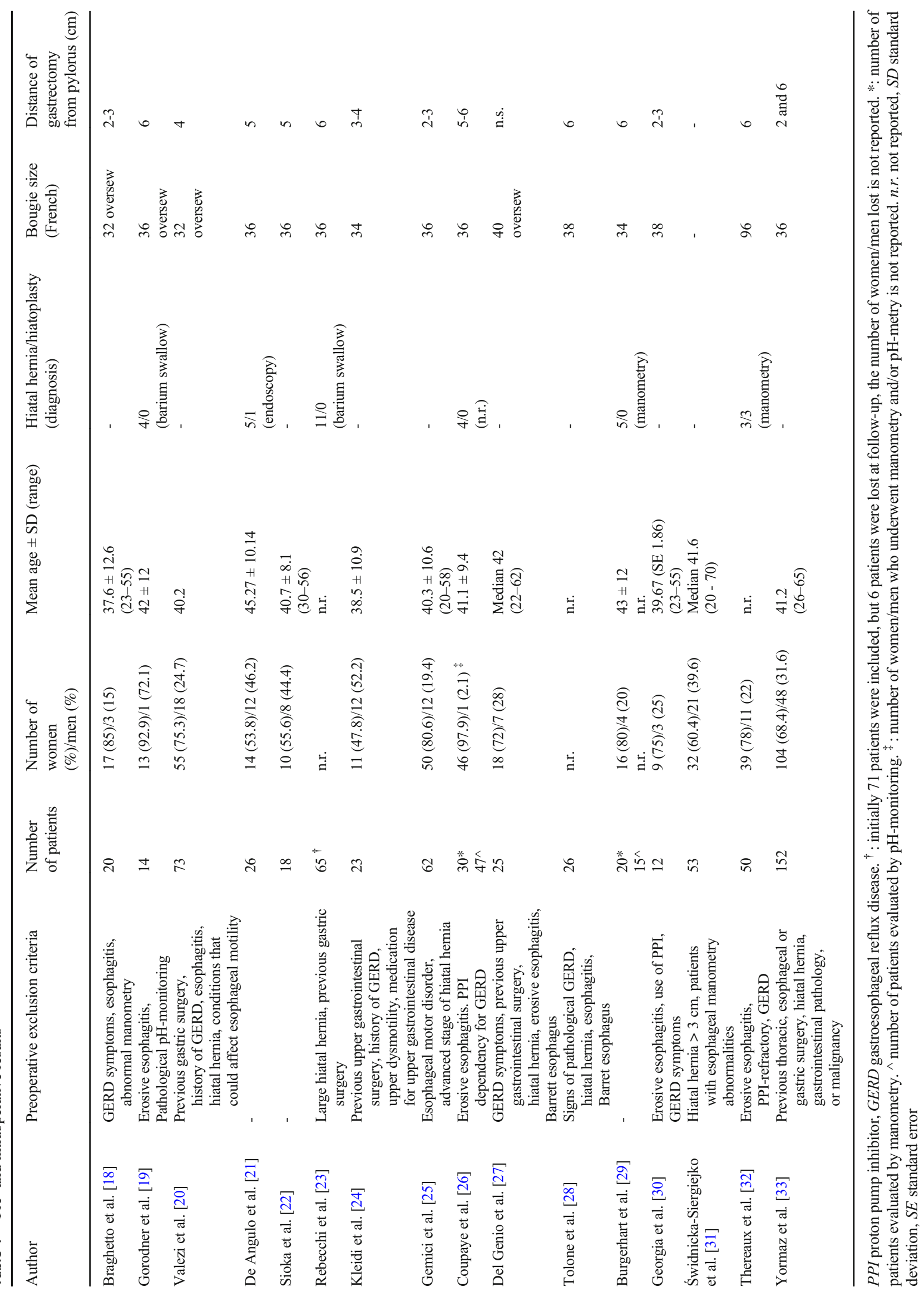




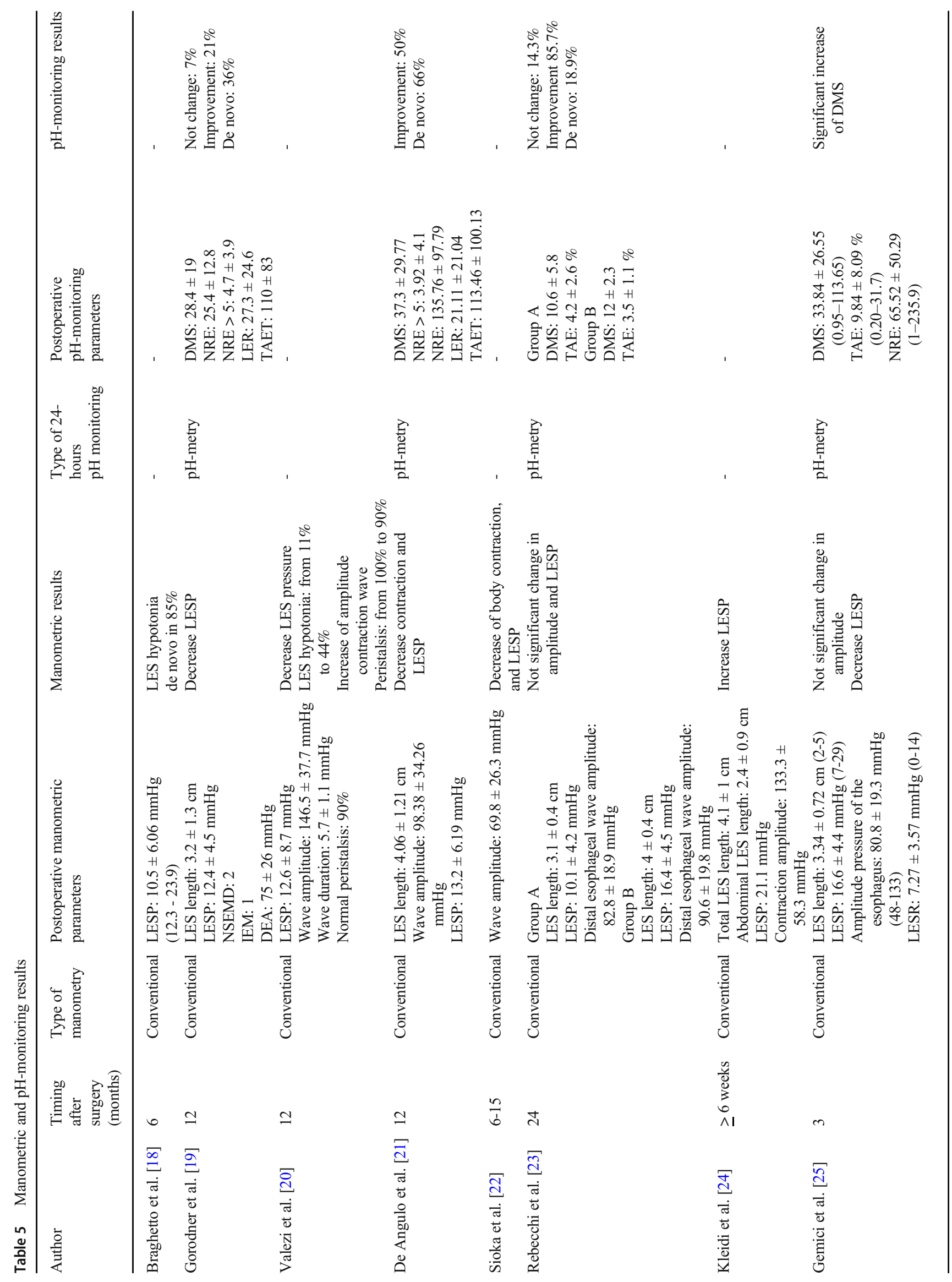




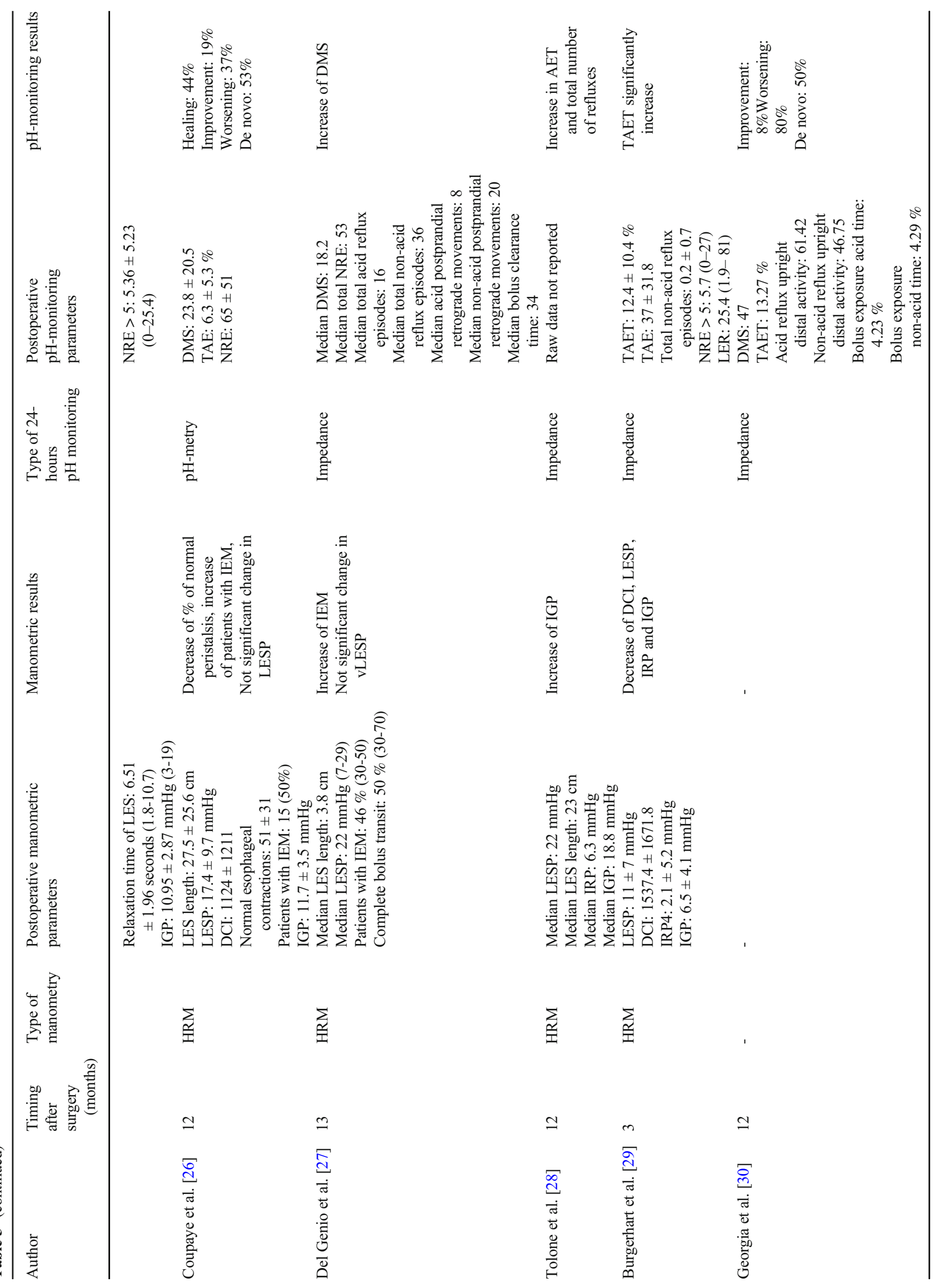




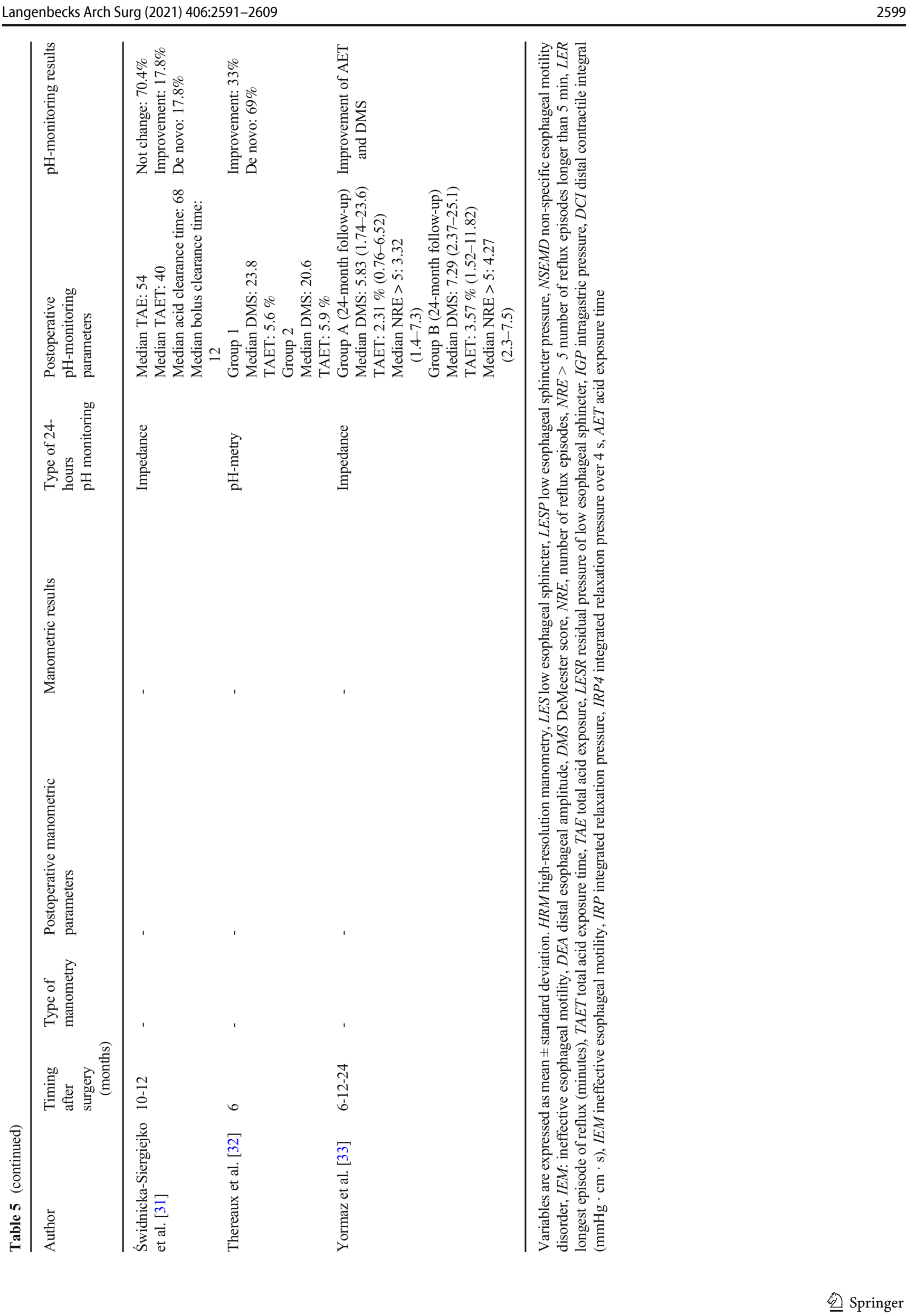


Fig. 2 Lower esophageal sphincter resting pressure trend

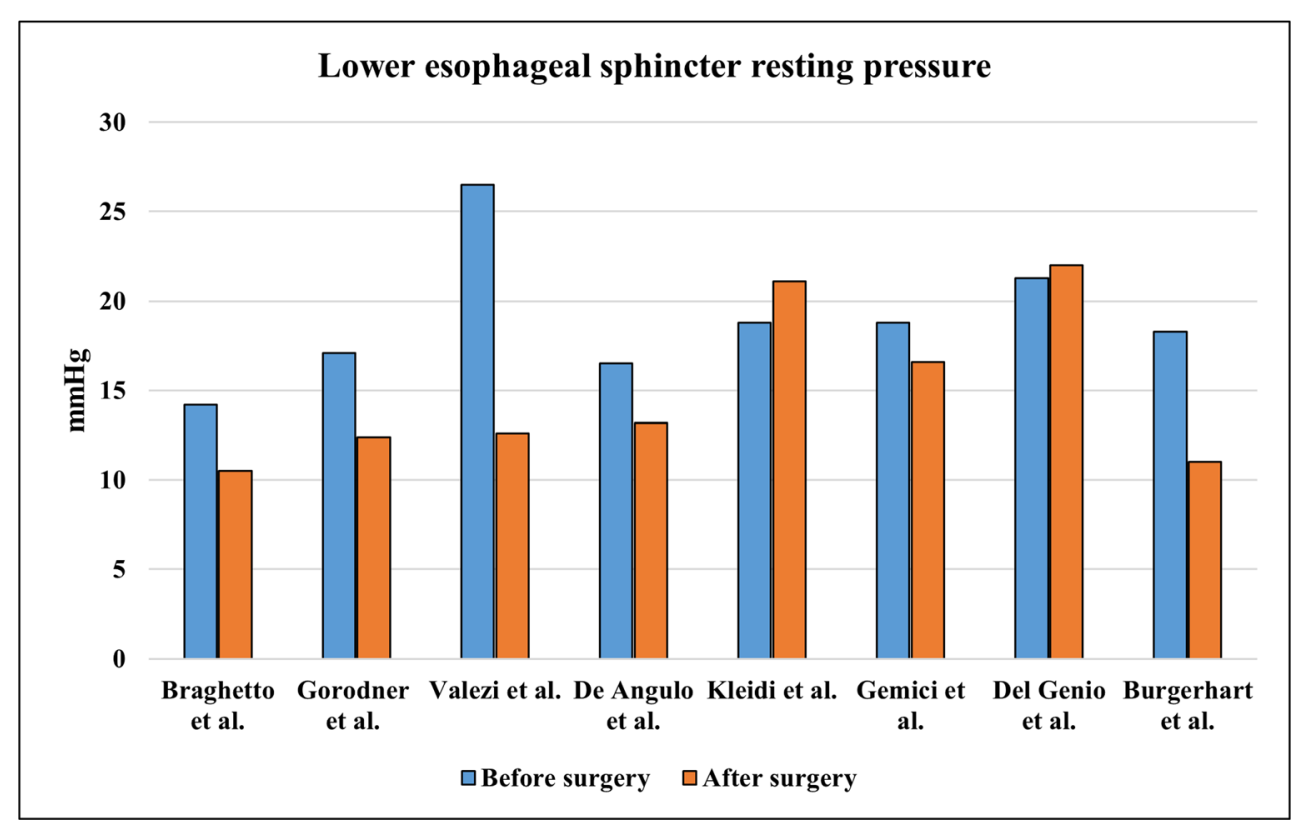

early functional evaluation was performed by Gemici et al. [25]. Sixty-two patients were evaluated 3 months after LSG, and the LES resting pressure significantly decreased from 18.8 to $16.6 \mathrm{mmHg}$ [25], with two patients developing a hypotensive LES [25]. Furthermore, prolonged LES relaxation time after swallowing was detected $(p=0.001)$ [25]. Other manometric findings, as total LES length, residual LES pressure, amplitude pressure of the esophagus, and intragastric pressure did not change at 3 months after LSG [25].

\section{High-resolution impedance manometry (HRiM)}

Data obtained from HRiM studies showed more changes in esophageal body peristalsis in comparison to LES pressure alterations [26-29] (Table 5). Coupaye et al. demonstrated significant worsening of peristalsis in a series of 30 patients [26]. Both the percentage of normal esophageal contractions within the ten analyzed swallows and the mean distal contractile integral (DCI) were decreased at 1 year after surgery [26]. Ineffective esophageal motility (IEM) was detected in 15 patients after LSG compared with 6 patients showing IEM prior to surgery $(p=0.048$ ); the percentage of patients with normal esophageal contractions prior to surgery was $71 \%$ compared with $51 \%$ observed 1 year after LSG [26]. There were no significant changes in LES resting pressure and esophagogastric junction contractile index (EGJ-CI) [26]. Interestingly, when a patients' subset-analysis based on the presence of GERD after surgery was performed, statistically significant esophageal motility changes were observed only in patients who developed de novo GERD after surgery [26]. Also, postoperative manometric hiatal hernia tended to be more frequent in patients with de novo GERD (55\% vs $9 \%$, $p=0.06)[26]$.
Similar results were reported by Del Genio et al. in a series of 25 patients who underwent HRiM before and after LSG, showing unchanged LES function after LSG [27]. Ineffective esophageal motility was detected in $46 \%$ of patients after surgery, as compared with $10 \%$ before surgery $(p=0.0001)$, and complete bolus transit rate decreased from $90 \%$ pre-surgery to $50 \%$ after surgery $(p=0.0001)$ [27].

Tolone et al. assessed the effect of different bariatric surgical techniques on EGJ and esophageal peristalsis in 112 obese patients, 26 of whom underwent LSG [28]. After LSG, there was no significant change in LES resting pressure, EGJ-CI, and integral relaxation pressure (IRP), but both intragastric pressure and gastroesophageal pressure gradient delta of pressure (GEPG $\Delta P$ ) were statistically significantly increased [28]. Unlike the absence of significant changes in LES metrics, esophageal peristalsis seems to be affected more by LSG: after surgery, ineffective esophageal motility waves were observed in $36 \%$ of patients [28].

Similar changes on LES metric were observed by Burgerhart et al. in a series of 20 patients [29]. Three months after surgery, statistically significant decrease in LES resting pressure and IRP were detected, from 18.3 to $11 \mathrm{mmHg}$ and from 6.5 to $2.1 \mathrm{mmHg}$, respectively [29]. Esophageal contractility also seemed affected, with a statistically significant decrease in the DCI value from 2006 to $1537 \mathrm{mmHg} \cdot \mathrm{cm} \cdot \mathrm{sec}$ [29].

The LES resting pressures before and after LSG in the included studies are reported in Fig. 2.

\section{4-hours pH-monitoring}

Twelve studies assessed ambulatory pH-monitoring before and after LSG in order to define its impact on GERD [19, 
Fig. 3 DeMeester score trend

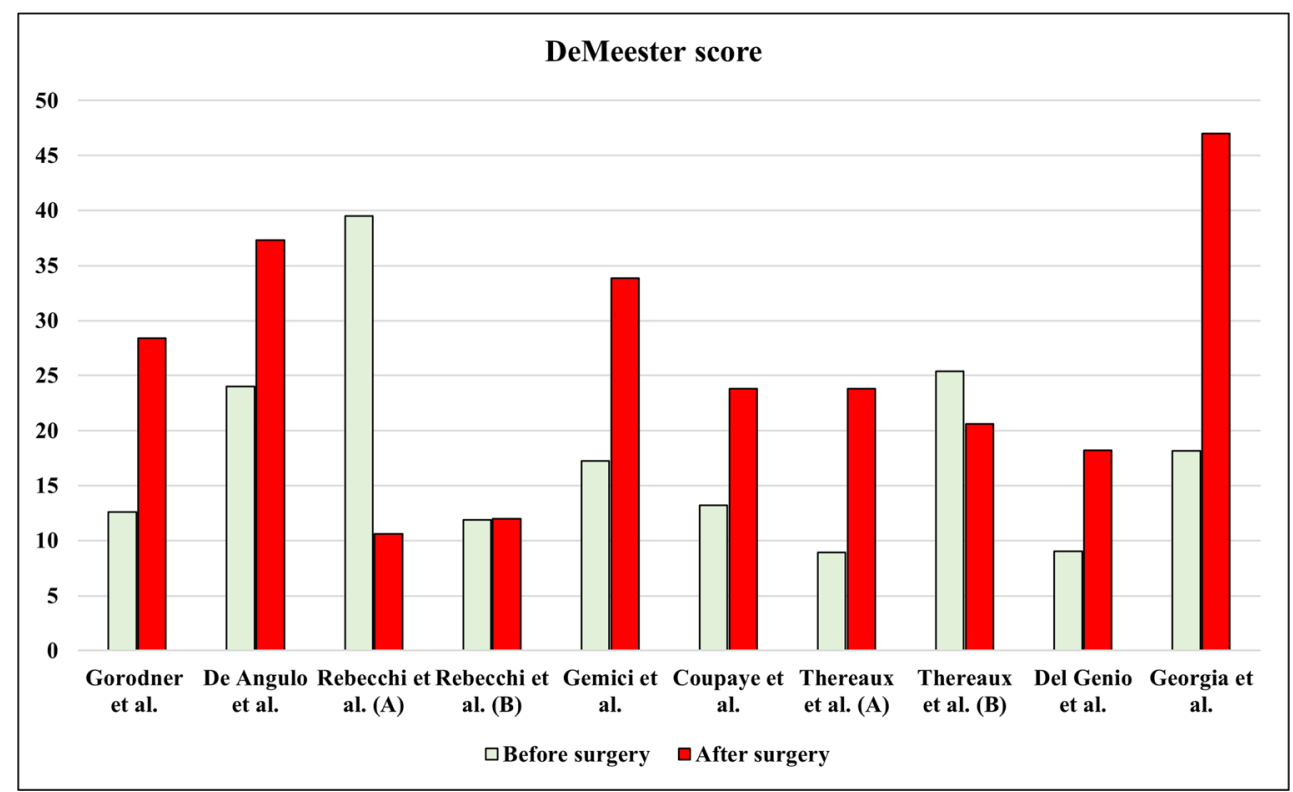

$21,23,25-33]$. In six studies, 24-hours $\mathrm{pH}$-monitoring was used [19, 21, 23, 25, 26, 32], whereas six more studies characterized GERD by 24-hours impedance-pH monitoring $[27-31,33]$. Six studies included patients independently from the presence of GERD [21, 23, 25, 29, 31, 33], whereas the other six articles excluded patients with a preoperative diagnosis of GERD based on the presence of erosive esophagitis, Barrett's esophagus, typical symptoms, or acid exposure at preoperative pH-monitoring [19, 26-28, 30, 32] (Table 5).

Gorodner et al. observed the most significant changes at pH-monitoring [19]. Increase in DeMeester score (DMS), total acid exposure time (AET), number of episodes longer than $5 \mathrm{~min}$, and duration of longest episode $(p=0.05)$ were detected 1 year after surgery [19]. Compared with preoperative results, GERD worsening and de novo GERD occurred in 21 and $36 \%$ of patients, respectively [19].

De Angulo et al. assessed GERD in a population of 26 obese patients who underwent LSG [21]. On reflux monitoring, an improvement of GERD was observed in half of patients, while the de novo GERD rate was 66\% [21]. An analysis of each $\mathrm{pH}$-monitoring parameters showed a statistically significant increase in DMS from 24.02 to 37.3 ( $p=0.028$ ). Other parameters, as total AET and number of refluxes did not change significantly [21].

Another prospective study including 65 consecutive patients showed a significant improvement of $\mathrm{pH}$-monitoring outcome measures after surgery in patients with GERD diagnosed prior to surgery [23]. At baseline, $42.3 \%$ of patients had pathologic pH-monitoring; a significant decrease in total AET and in DMS were demonstrated 2 years after surgery, and pathological reflux persisted only in $14.3 \%$ of these patients [23]. On the other hand, patients with normal $\mathrm{pH}$-monitoring before surgery (57.7\%) developed de novo GERD in $18.9 \%$ of cases [23]. Of note, the mean value of DMS and of the total AET did not change significantly after LSG in this group [23].

Gemici et al. evaluated a cohort of 62 obese patients 3 months after surgery, observing the statistically significant increase of several $\mathrm{pH}$-monitoring parameters: DMS, total AET, total number of acid reflux episodes longer than 5 min, and duration of the longest reflux episode [25]. At multivariate analysis, the number of refluxes longer than $5 \mathrm{~min}$ was the parameter that influenced most the DMS (odds ratio: 1.866) [25].

Coupaye et al. evaluated a consecutive series of 47 patients before and 1 year after surgery [26]. The study design excluded patients with erosive esophagitis or under proton pump inhibitor (PPI) therapy for GERD [26]. After surgery, significant increase in total AET and in DMS was observed in the entire cohort [26]. However, when patients were stratified based on baseline reflux monitoring, the parameters of reflux changed significantly only in the group of patients without baseline GERD [26]. In this group, DMS increased from 7.5 to 22.3 and total AET increased from 1.8 to $5.8 \%(p=0.001)$, whereas no significant increase was observed in patients with baseline GERD [26].

These results do not differ when early functional evaluation was performed [32]. Thereaux et al. observed de novo GERD in a consistent number of patients 6 months after surgery [32]. Fifty patients underwent $\mathrm{pH}$-monitoring before and after surgery [32]. DMS and total AET increased after surgery in patients without preoperative GERD, whereas a significant reduction of the same outcome was detected in GERD patients [32]. In multivariable analysis, lower preoperative percentage of total time spent with esophageal $\mathrm{pH}<4$ was significantly associated with higher absolute variation after surgery in the 
Table 6 SymptomLate esophagogastric anatomic and s evaluation

\begin{tabular}{|c|c|c|c|}
\hline Author & Symptom assessment tool & Preoperative results & Postoperative results \\
\hline Braghetto et al. [18] & - & - & - \\
\hline Gorodner et al. [19] & Standard questionnaire & $\begin{array}{l}\text { Heartburn: } 0.4 \pm 0.9 \\
\text { Regurgitation: } 0.5 \pm 1 \\
\text { Chest pain: } 0.1 \pm 0.3 \\
\text { Dysphagia: - } \\
\text { Cough: } 0.2 \pm 0.8\end{array}$ & $\begin{array}{l}\text { Heartburn: } 0.5 \pm 1.2 \\
\text { Regurgitation: } 0.4 \pm 0.6 \\
\text { Chest pain: } 0.2 \pm 0.8 \\
\text { Dysphagia: - } \\
\text { Cough: } 0\end{array}$ \\
\hline Valezi et al. [20] & - & - & - \\
\hline De Angulo et al. [21] & Presence of heartburn and regurgitation & $\begin{array}{l}\text { Heartburn: } 12 \text { patients } \\
\text { Regurgitation: } 9 \text { patients }\end{array}$ & $\begin{array}{l}\text { Heartburn: } 10 \text { patients } \\
\text { Regurgitation: } 10 \text { patients }\end{array}$ \\
\hline Sioka et al. [22] & $\begin{array}{l}\text { Reflux symptoms assessment } \\
\text { questionnaire }\end{array}$ & - & $\begin{array}{l}\text { Heartburn: } \\
\text { - Improvement: } 7 \text { patients } \\
\text { - No change: } 9 \text { patients } \\
\text { - Worsening: } 2 \text { patients } \\
\text { Regurgitation: } \\
\text { - Improvement: } 2 \text { patients } \\
\text { - No change: } 11 \text { patients } \\
\text { - Worsening: } 5 \text { patients }\end{array}$ \\
\hline Rebecchi et al. [23] & $\begin{array}{l}\text { Gastroesophageal Reflux Disease } \\
\text { Symptom Assessment Scale } \\
\text { (GSAS) }\end{array}$ & $\begin{array}{l}\text { Group A: } 53.1 \pm 10.5 \\
\text { Group B: } 45.8 \pm 9.6\end{array}$ & $\begin{array}{l}\text { Group A: } 13.1 \pm 3.5 \\
\text { Group B: } 31.7 \pm 15.9\end{array}$ \\
\hline Kleidi et al. [24] & Likert scale & Total score: $4.9 \pm 1.6$ & Total score: $5.8 \pm 1.3$ \\
\hline Gemici et al. [25] & - & - & - \\
\hline Coupaye et al. [26] & Presence of heartburn and regurgitation & 6 patients & 18 patients \\
\hline Del Genio et al. [27] & Standard questionnaire & - & $\begin{array}{l}\text { No modification of } \\
\text { symptoms incidence }\end{array}$ \\
\hline Tolone et al. [28] & GERDQ questionnaire & n.r. & n.r. \\
\hline Burgerhart et al. [29] & Reflux Disease Questionnaire (RDQ) & GERD score: $7.7 \pm 8.3$ & GERD score: $7.6 \pm 6.3$ \\
\hline Georgia et al. [30] & - & - & - \\
\hline $\begin{array}{l}\text { Świdnicka-Siergiejko } \\
\text { et al. [31] }\end{array}$ & GERDQ questionnaire & Median 6.5, IQR 6-7 & Median 6.7, IQR 6-8 \\
\hline Thereaux et al. [32] & $\begin{array}{l}\text { Presence of heartburn, regurgitation, } \\
\text { or dysphagia }\end{array}$ & 17 patients & 29 patients \\
\hline Yormaz et al. [33] & Reflux Symptom Index (RSI) & n.r. & $\begin{array}{l}\text { Group A } \\
-24 \text { months: } 25 \pm 2.2 \\
\text { Group B } \\
-24 \text { months: } 26.4 \pm 2.1\end{array}$ \\
\hline
\end{tabular}

Variables are expressed as mean \pm standard deviation. IQR interquartile range, GERD gastroesophageal reflux disease, n.r. not reported

percentage of total time spent with esophageal $\mathrm{pH}<4$, regardless of age, sex, and percentage total weight loss [32].

\section{4-hours impedance-pH monitoring}

Interesting findings stemmed from impedance-pH monitoring outcome analysis [27-31, 33] (Table 5). Del Genio et al. reported statistically significant increase in the total number of acid and non-acid reflux episodes in 25 obese patients after LSG at 1 year after surgery, as well as increased acid and nonacid postprandial retrograde movements and esophageal bolus clearance time [27].

Tolone et al. assessed ambulatory impedance-pH monitoring 1 year after surgery in a cohort of 26 patients [28]. The study design included only patients without baseline pathological impedance-pH monitoring. After surgery, significant increase in total AET $(p=0.05)$ and in total number of reflux $(p=0.001)$ was observed [28]. The rate of de novo GERD was not estimated [28].

Burgerhart et al. carried out an evaluation 3 months after LSG in a series of 15 patients and reported an increase in total AET from 4.1 to $12 \%(p=0.004)$ [29]. In addition, an increase in the number of long refluxes and in their mean duration was observed [29]. The authors hypothesized that this might be due to decreased acid clearance in the distal esophagus and/ or ongoing reflux because of a new reflux episode within an earlier episode (re-reflux), as possible mechanisms of worsening GERD [29]. 
Georgia et al. reported a statistically significant increase in total AET (from 3.87 to $13.27 \%, p=0.048$ ) in a series of 12 patients after LSG, and de novo GERD occurred in $50 \%$ of patients [30]. According to impedance-pH monitoring, the mean number of non-acid reflux episodes increased, while no differences were reported from the analysis of acid reflux [30]. Furthermore, both bolus exposure acid and non-acid percentage times were significantly increased [30].

Świdnicka-Siergiejko et al. evaluated a cohort of 53 patients who underwent LSG [31]. Based on impedance-pH monitoring, GERD was present in $60.4 \%$ of patients before surgery [31]. Outcomes 1 year after surgery showed an improvement in $17.8 \%$ of patients with preoperative GERD, and de novo GERD was observed in $17.8 \%$ of patients [31]. When the whole population was analyzed regardless of baseline reflux monitoring, only the total number of reflux episodes was significantly reduced, whereas significant changes in the median percentage of esophageal AET, acid clearance time, or bolus clearance time were not observed [31].

Yormaz et al. reported a significant improvement of GERD parameters [33]. The study design included 152 patients assessed by impedance-pH monitoring at 6,12 , and 24 months after surgery [33]. In the whole cohort, DMS, total AET and number of refluxes lasting longer than $5 \mathrm{~min}$ decreased significantly at 6 and 12 months, whereas no significant changes were observed at 24 months after surgery [33]. According to the authors, the observed changes depended on the surgical technique that was used [33]. The decrease of GERD parameters was higher when gastric resection started $2 \mathrm{~cm}$ from the pylorus rather than $6 \mathrm{~cm}$ [33]. The mean DMS decreased from 45.32 preoperatively to 32.27 at 6 months and to 14.42 at 1 year after LSG [33]. Although the improvement was significant, the mean score persisted pathological, and this was observed also in the group with gastric resection starting at $6 \mathrm{~cm}$ from the pylorus [33].

Figure 3 shows the trend in DMSs.

\section{Symptoms evaluation}

Symptoms were evaluated in 11 articles [19, 21-24, 26, 27 , 29, 31-33] (Table 6). Eight articles [19, 22-24, 27, 29, 31, 33] employed questionnaires for symptoms evaluation, while the remaining three articles evaluated the presence of symptoms $[21,26,32]$. Overall, in most of the included articles, important modifications of symptoms were not observed [19, 21, $22,24,27,29,31$ ], worsening of symptoms was reported in two articles [26, 32], and improvement of symptoms was reported in one [23] (Table 6). Symptoms trend seems to be similar to the $\mathrm{pH}$-manometric evaluation in seven articles [22-24, 26, 27, 31, 32], while in the remaining three articles, symptoms are not related to the instrumental data [19, 21, 29].

\section{Discussion}

The aim of this systematic review was to investigate the manometric and $\mathrm{pH}$-monitoring changes after LSG. Even if the evaluation was heterogeneous among the included studies, overall, it seems that LSG has a negative impact on gastroesophageal reflux evaluated both with manometry and 24hours pH-monitoring. For a more objective evaluation, we decided to exclude studies in which the analysis was based only on symptoms and on endoscopic findings. In fact, endoscopy may describe only the presence of erosive esophagitis, which is detected only in about $50 \%$ of patients with GERD, while 24-hours impedance-pH may also identify non-erosive reflux disease (NERD) with 92\% sensitivity rate [34]. Moreover, due to early timing of postoperative endoscopic evaluation reported in the included studies, it is possible that gastroesophageal reflux may not have caused overt damage of the esophageal mucosa yet. For this reason, and for more objective evaluation of the postoperative changes, only studies that reported data of manometry and 24-hours pH-monitoring detected before and after surgery were included.

In our opinion, to define a clear recommendation on the impact of LSG on gastroesophageal reflux, research efforts should be aimed at knowing the position and tone of the EGJ, if there are any modifiable surgical aspects that are involved and if there are any detectable factors prior to surgery that may predict the possible drawbacks of LSG. For this purpose, manometry and 24-hours impedance-pH monitoring are the best instrumental exams that are available [35-38]. Esophageal manometry can detect functional esophageal and EGJ abnormalities which could be involved in the pathophysiology of GERD [35-37]. 24-hours impedance-pH monitoring is the gold standard for detection and characterization of reflux episodes [38]. The impedance-pH monitoring assesses reflux events with both a $\mathrm{pH}$ electrode and a series of impedance electrodes [38]. Unlike conventional manometry, this technique provides a more complete evaluation of reflux episodes, which includes weakly acidic and alkaline reflux, liquid gaseous refluxes or both, and re-reflux episodes [38].

The major concern after LSG is the development of GERD, but its pathophysiology and prevalence after surgery are not well understood [39].

The anti-reflux mechanisms involve (i) anatomical structures, such as the EGJ, composed of the intrinsic LES and diaphragmatic crura, the phrenoesophageal ligament, the acute angle of His, and (ii) functional barriers such as the functional efficacy of the EGJ and the esophageal peristalsis clearing the refluxate from the esophageal lumen to the stomach [38].

LSG may modify the anti-reflux mechanisms at different levels resulting in an increased risk of developing GERD [8, 13]. For this reason, in obese patients with complicated GERD, as severe erosive disease or Barrett's esophagus, 
LRYGB is usually preferred $[1,9-11,40]$. However, because of the heterogeneity of the available studies, the prevalence of GERD occurring after LSG is still not well defined [39].

Several questions have recently stimulated medical research on this topic: is LSG responsible for GERD? Which alterations can occur after LSG and which alterations can contribute to GERD development? Could surgical technical aspects cause functional and/or anatomical changes, which may be responsible for GERD pathophysiology? Are there any baseline functional abnormalities which are predictors of the development of GERD after LSG?

Studies including functional testing before and after LSG were selected to provide an objective assessment of reflux disease and to try to explain its pathophysiology [18-33]. Data analysis was hampered by a lack of standardization both in re-assessment timing, ranging from 6 weeks to 24 months after surgery, and in the type of outcomes that were evaluated [18-33]. Because of possible anatomical adaptations occurring over time after surgery, it might be incorrect to equate early and late evaluation.

\section{Esophageal manometry}

A functional evaluation of the main components of the antireflux mechanisms, as provided by esophageal manometry, could be useful to understand the pathophysiology of GERD $[35,41]$. GERD may be associated with hypomotility and structural mechanisms involving both esophageal peristalsis and the EGJ [35]. It must be considered that the normal range values are defined in "healthy" patients who did not undergo surgery [41]; the anatomical implication of LSG creates a new "system," and standardized normal values might not be valid in this condition. Normal values refer to asymptomatic subjects, free of systemic pathologies that may affect muscle motor activity or neurological control, who have not previously undergone surgery.

Therefore, the data collected at manometry after surgery must include the following: (1) if there is a more or less stable variation of the recorded variables with respect to the normal ranges; (2) if the "different" adjustment of the values is associated with the presence of symptoms and in this case of GERD; and (3) if a cut-off is identifiable with respect to which of the variations may become the cause of symptoms or in any case of prolonged acid exposure or reflux to the esophageal mucosa.

The relationship between GERD and esophageal body peristalsis impairment is not yet well characterized. Whether the alteration of peristalsis is a cause or a consequence of GERD is still debated; more specifically, is not clear if impairment of peristalsis promotes GERD or if GERD, resulting from other injured anti-reflux mechanisms, may translate into worse peristalsis [42].
The association between GERD and esophageal body peristalsis abnormalities has been demonstrated by several studies [43-46]. The burden of reflux disease increases progressively based on the type of esophageal body motility disorders, from fragmented peristalsis, followed by ineffective esophageal motility, and by absent contractility [47]. Rengarajan et al. demonstrated that failed more than weak peristalsis is associated with reflux burden, probably because of more severe dysmotility which affects both primary and secondary peristalsis and consequently reduces the reflux clearance [42]. One study found significant correlations between manometric and impedance-pH-metric outcomes: AET, number of longterm acid reflux episodes, and number of weakly acid reflux episodes were found to be negatively correlated with esophageal body motility [48]. Most of the included studies reported an impaired peristalsis regarding the amplitude of contractions, by conventional manometry, and DCI by HRM [18-33]. This data is more evident in the pre-LES distal portion of the esophageal body. The reduced or ineffective peristalsis could be an adaptation to the pressure reduction of the EGJ, but in this case it becomes a vicious circle because this situation could lead to ineffective clearing and therefore to a prolonged time of acid exposure.

The effectiveness of the anti-reflux barrier, as well as the severity of reflux, is dependent on function or dysfunction of each individual components of the anti-reflux barrier [35]. A complete characterization of the EGJ should include an evaluation of EGJ-CI and of EGJ morphology which may help to discriminate normal from abnormal barrier functions [35]. Although to date standardized calculation methodology and normative value of EGJ-CI are lacking [41], a lower value of EGJ-CI was observed in patients with pathological AET [49]. Furthermore, Gor et al. demonstrated that EGJ-CI discriminated normal from abnormal AET better than conventional LES parameters [50]. Interestingly, a recent study suggests that lower EGJ-CI affects GERD burden especially if an esophageal body motility dysfunction coexists [42]. EGJ morphology also affects effectiveness of the anti-reflux barrier [51, 52]. Based on overlap or separation between the intrinsic LES and the crural diaphragm (CD), three types of EGJ are defined [52]. In type I EGJ, these structures are overlapping, whereas type III consists of $3 \mathrm{~cm}$ or greater separation between the intrinsic LES and CD [52]. Type III EGJ is associated with reflux burden $[35,42]$. Low LES resting pressure is more likely in patients with erosive reflux disease and in patients who are candidates to reflux surgery [53,54], suggesting that a hypotensive LES is associated with higher severity of GERD [36, 37].

The impact of LSG on EGJ-CI and EGJ morphology are not yet well studied [18-33]. In our systematic review, only two studies assessed EGJ-CI and EGJ morphology, and significant changes after surgery nor correlation with pathological reflux monitoring were not observed [26, 28]. Further 
studies, including complete and standardized evaluation of esophageal motility are required.

Table 5 summarizes the main changes detected by esophageal manometry after LSG. Regarding esophageal peristalsis, an increase of IEM diagnosis and a reduction in contraction amplitude or in DCI, as expression of contraction vigor, were demonstrated [21, 22, 24, 26-29]. The IEM rate after LSG was reported to occur between 36 and $50 \%$ of cases [26-28]. A decrease in DCI was also found [29], together with a decrease in contraction amplitude measurements when conventional manometry was performed [21, 22, 24].

LSG seems to be associated with impaired esophageal peristalsis [28]. Tolone et al. demonstrated an increase of proximal intragastric pressure and gastro-esophageal pressure gradient after LSG [28]. These changes must be considered when contraction amplitude and LES pressure are assessed after surgery [28]. Furthermore, impedance HRM showed significant worsening of complete bolus transit compared to baseline [28]. These data suggest that although the esophagus encounters a greater gastric obstacle to empty itself, it does not react by increasing the force of contraction, but rather it produces a slowed esophageal transit. At $\mathrm{pH}$-reflux monitoring, an increase of superimposed reflux is detected, and number of refluxes longer than $5 \mathrm{~min}$ are the most influencing parameters of the DMS [29]. This suggests that a reduction in the clearance of reflux is the main cause of GERD onset; probably a more vigorous esophageal contraction is needed to clear the reflux.

A decrease in mean LES tone value was observed in seven of twelve studies [18-22, 25, 29]; three of them detected and estimated the de novo hypotensive LES rate [18-20]. This result could be more clinically relevant than the reduction in mean LES tone value, especially when a pathologic lower value is not reached [41]. De novo hypotensive LES rate detection ranged from 25 to $85 \%$ [18-20]. LSG could directly affect LES pressure; Braghetto et al. speculated that partial resection of the sling fibers during surgery might be the cause of a hypotensive LES and de novo GERD might be due to this anatomical, and consequently functional, impairment [18].

\section{4-hours pH-monitoring}

The impact of LSG on esophageal function involves not only the esophageal motility but also the reflux burden [39]. The relationship between $\mathrm{pH}$-monitoring outcomes and manometric findings is difficult to assess [39]. Data from impedance$\mathrm{pH}$ monitoring show an increase in the number of acid and non-acid reflux episodes suggesting anatomical consequences, including decreased compliance as a cause of this $[27,28]$. Also, an increase in esophageal bolus clearance time was demonstrated [27]; maybe, in this "new" anatomical condition, more vigorous esophageal peristalsis is needed to contrast reflux.
In nine out of twelve included studies, an increase of DMS and/or total AET was observed after LSG [19, 21, 25-30, 32]. On the contrary, two studies [23, 33] detected a decrease in these outcomes while one study reported no difference in the observed DMS and AET, although a reduction in the number of refluxes was demonstrated [31].

Considering the findings of baseline pH-metry, a decrease in total AET is the only factor that is associated with a significant absolute variation after surgery [22]. This result supports the evidence that patients without GERD are more likely to develop reflux after surgery than patients with baseline GERD to worsen.

De novo GERD is the major drawback that can occur after LSG, probably due to anatomical changes that could affect the anti-reflux barrier [18]. The incidence of symptomatic de novo GERD after LSG ranges between 0 and 34.9\% [39]. As shown in Table 5, in this systematic review, the de novo GERD rate is wide and ranges from 17.8 to $69 \%$ [18-33]. Patients with baseline GERD after LSG may show worsening, improvement, or healing: the improvement rate ranges from 8 to $85 \%$, and one study showed healing in $44 \%$ of patients [26]. Detection of de novo GERD may be clinically more relevant than the worsening of single parameters. The worsening of pH-metric outcomes, as DMS or AET, can be a notable result if clinical and endoscopic parameters worsen, including symptoms or the rate of erosive esophagitis; otherwise, its clinical impact could be irrelevant. The presence of different "mechanisms" involved in reflux disease could explain these findings. De novo GERD could arise from an anti-reflux system injury during surgery, while patients with baseline pathologic reflux monitoring probably had GERD risk factors, which are not affected by LSG. It may be hypothesized that obesity is the main risk factor involved in GERD for this group of patients and that BMI reduction after surgery may improve GERD in some patients, even if this is not confirmed by the present study [18-33].

Compared to restrictive-malabsorptive surgery, as LRYGB, a restrictive surgery as LSG seems to have a higher risk of developing GERD [28]. A recent trial demonstrated a de novo GERD rate of $31.6 \%$ after LSG compared to $10.7 \%$ after LRYGB $(p=0.01)$ and the need for conversion to LRYGB due to GERD in $9 \%$ of patients who underwent LSG [40].

\section{Symptoms}

Overall, symptom evaluation in the included studies departs from instrumental GERD assessment [19, 21-24, 26, 27, 29, 31-33]. Currently, endoscopy and pH-manometry are not routinely recommended according to the American Society for Metabolic \& Bariatric Surgery (ASMBS) and the European Association for Endoscopic Surgery (EAES) guidelines in patients candidate for bariatric surgery as well postoperatively 
$[55,56]$. So, the indication for LSG or LRYGB and the evaluation of GERD after surgery are based on what patients report, with low reliability [34, 55-59]. This lack of instrumental evaluation could be responsible for controversial data on GERD after LSG [23, 26, 60, 61]. In our opinion, a standardized instrumental evaluation before and after surgery would clarify the impact of LSG on GERD, leading to offer patients a higher postoperative quality of life and a reduced risk of Barrett's esophagus.

\section{Limitations}

Due to the heterogeneity of data obtained from the included studies, it was not possible to statistically analyze if bougie size, distance of gastrectomy from the pylorus, and postoperative BMI had an impact on postoperative GERD. Anyway, based on this review, these variables do not seem to influence the results.

The main limitations of the present systematic review are the small sample of patients for each included article, the heterogeneity of data reported, and the poor quality of the included papers. Moreover, the timing for postoperative GERD evaluation is not standardized, as well as the type of instruments and questionnaires used for GERD evaluation. The abovementioned limitations affect the statistical analysis and make a meta-analysis impossible, thereby making it difficult to draw firm conclusions.

\section{Conclusions}

After LSG a worsening of GERD evaluated by instrumental exams was observed, with a high prevalence of de novo GERD, despite a similar worsening of symptoms was not observed. However, to understand the clinical impact of LSG and the burden of GERD over time, further studies with long-term follow-up are necessary. Concerning GERD pathophysiology, some functional/motility alterations involving the esophageal body peristalsis, the EGJ, or both occur after surgery, but the consequences on GERD development are difficult to define. To understand the clinical impact of each esophageal motility change, the anatomical changes that occur after LSG ought to be considered. It is possible to speculate that a new anatomical EGJ formed after LSG, and the new pressure or pressure gradient could influence the reflux pathophysiology differently. On these grounds, the standardized values defined in patients with a physiologic EGJ could not be valid for patients who underwent LSG. More vigorous esophageal contractions and a higher EGJ pressure could be necessary to contrast the reflux.
To our knowledge, to date functional testing seems to be unable to identify predictors for GERD development or which patients will develop GERD after LSG more easily. However, more accurate and standardized assessments of the EGJ with new promising metrics, as EGJ-CI, could add further information to predict GERD development after LSG.

Authors' Contributions A.B participated in study conception and design. A.B, F.M, L.P, D.C, M.C. S, E.R, D.C, A.P, D.B, and A.M. P participated in acquisition of data, analysis and interpretation of data, drafting of manuscript, critical revision of manuscript, and final approval.

Funding Open access funding provided by Università degli Studi di Roma La Sapienza within the CRUI-CARE Agreement.

\section{Declarations}

Ethical approval All procedures performed in this study involving human participants were in accordance with the ethical standards of the institutional and/or national research committee and with the 1964 Helsinki Declaration and its later amendments or comparable ethical standards. For this type of study formal consent is not required.

Conflict of interest The authors declare no competing interests.

Open Access This article is licensed under a Creative Commons Attribution 4.0 International License, which permits use, sharing, adaptation, distribution and reproduction in any medium or format, as long as you give appropriate credit to the original author(s) and the source, provide a link to the Creative Commons licence, and indicate if changes were made. The images or other third party material in this article are included in the article's Creative Commons licence, unless indicated otherwise in a credit line to the material. If material is not included in the article's Creative Commons licence and your intended use is not permitted by statutory regulation or exceeds the permitted use, you will need to obtain permission directly from the copyright holder. To view a copy of this licence, visit http://creativecommons.org/licenses/by/4.0/.

\section{References}

1. Balla A, Quaresima S, Palmieri L, Seitaj A, Pronio A, Badiali D, Fingerhut A, Ursi P, Paganini AM (2019) Effects of laparoscopic sleeve gastrectomy on quality of life related to gastroesophageal reflux disease. J Laparoendosc Adv Surg Tech A 29(12):15321538. https://doi.org/10.1089/lap.2019.0540

2. Hendricks L, Alvarenga E, Dhanabalsamy N, Lo Menzo E, Szomstein S, Rosenthal R (2016) Impact of sleeve gastrectomy on gastroesophageal reflux disease in a morbidly obese population undergoing bariatric surgery. Surg Obes Relat Dis 12:511-517. https://doi.org/10.1016/j.soard.2015.08.507

3. Moon RC, Teixeira AF, Jawad MA (2015) Is preoperative manometry necessary for evaluating reflux symptoms in sleeve gastrectomy patients? Surg Obes Relat Dis 11:546-551. https://doi.org/10. 1016/j.soard.2014.07.014

4. Hawasli A, Bush A, Hare B, Meguid A, Thatimatla N, Szpunar S (2015) Laparoscopic management of severe reflux after sleeve 
gastrectomy, in selected patients, without conversion to Roux-en-y gastric bypass. J Laparoendosc Adv Surg Tech 25:631-635. https:// doi.org/10.1089/lap.2015.0079

5. Borbély Y, Schaffner E, Zimmermann L, Huguenin M, Plitzko G, Nett P, Kröll D (2019) De novo gastroesophageal reflux disease after sleeve gastrectomy: role of preoperative silent reflux. Surg Endosc 33:789-793. https://doi.org/10.1007/s00464-018-6344-4

6. Balla A, Batista Rodríguez G, Corradetti S, Balagué C, FernándezAnanín S, Targarona EM (2017) Outcomes after bariatric surgery according to large databases: a systematic review. Langenbecks Arch Surg 402(6):885-899. https://doi.org/10.1007/s00423-0171613-6

7. Khorgami Z, Shoar S, Andalib A, Aminian A, Brethauer SA, Schauer PR (2017) Trends in utilization of bariatric surgery, 2010-2014: sleeve gastrectomy dominates. Surg Obes Relat Dis 13(5):774-778. https://doi.org/10.1016/j.soard.2017.01.031

8. Daher HB, Sharara AI (2019) Gastroesophageal reflux disease, obesity and laparoscopic sleeve gastrectomy: the burning questions. World J Gastroenterol 25:4805-4813. https://doi.org/10.3748/wjg. v25.i33.4805

9. Salvador-Sanchis JL, Martinez-Ramos D, Herfarth A, RivadullaSerrano I, Ibañez-Belenguer M, Hoashi JS (2010) Treatment of morbid obesity and hiatal paraesophageal hernia by laparoscopic Roux-en-y gastric bypass. Obes Surg 20(6):801-803. https://doi. org/10.1007/s11695-008-9656-y

10. Balla A, Quaresima S, Ursi P, Seitaj A, Palmieri L, Badiali D, Paganini AM (2017) Hiatoplasty with crura buttressing versus hiatoplasty alone during laparoscopic sleeve gastrectomy. Gastroenterol Res Pract 2017:6565403. https://doi.org/10.1155/ 2017/6565403

11. Biter LU, van Buuren MMA, Mannaerts GHH, Apers JA, Dunkelgrün M, Vijgen GHEJ (2017) Quality of life 1 year after laparoscopic sleeve gastrectomy versus laparoscopic Roux-en-y gastric bypass: a randomized controlled trial focusing on gastroesophageal reflux disease. Obes Surg 27(10):2557-2565. https:// doi.org/10.1007/s11695-017-2688-4

12. Stenard F, Iannelli A (2015) Laparoscopic sleeve gastrectomy and gastroesophageal reflux. World J Gastroenterol 21(36):1034810357. https://doi.org/10.3748/wjg.v21.i36.10348

13. Braghetto I, Korn O (2019) Late esophagogastric anatomic and functional changes after sleeve gastrectomy and its clinical consequences with regards to gastroesophageal reflux disease. Dis Esophagus 32(6):doz020. https://doi.org/10.1093/dote/doz020

14. Moher D, Liberati A, Tetzlaff J, Altman DG (2010) Preferred reporting items for systematic reviews and meta-analyses: the PRISMA statement. Int J Surg 8:336-341. https://doi.org/10. 1016/j.ijsu.2010.02.007

15. Goossen K, Tenckhoff S, Probst P, Grummich K, Mihaljevic AL, Büchler MW, Diener MK (2018) Optimal literature search for systematic reviews in surgery. Langenbecks Arch Surg 403(1):119129. https://doi.org/10.1007/s00423-017-1646-x

16. Lo CK, Mertz D, Loeb M (2014) Newcastle-Ottawa scale: comparing reviewers' to authors' assessments. BMC Med Res Methodol 14:45. https://doi.org/10.1186/1471-2288-14-45

17. Sterne JA, Hernán MA, Reeves BC, Savović J, Berkman ND, Viswanathan M, Henry D, Altman DG, Ansari MT, Boutron I, Carpenter JR, Chan AW, Churchill R, Deeks JJ, Hróbjartsson A, Kirkham J, Jüni P, Loke YK, Pigott TD, Ramsay CR, Regidor D, Rothstein HR, Sandhu L, Santaguida PL, Schünemann HJ, Shea B, Shrier I, Tugwell P, Turner L, Valentine JC, Waddington H, Waters E, Wells GA, Whiting PF, Higgins JP (2016) ROBINS-I: A tool for assessing risk of bias in non-randomised studies of interventions. BMJ. 355:4-10. https://doi.org/10.1136/bmj.i4919
18. Braghetto I, Lanzarini E, Korn O, Valladares H, Molina JC, Henriquez A (2010) Manometric changes of the lower esophageal sphincter after sleeve gastrectomy in obese patients. Obes Surg 20: 357-362. https://doi.org/10.1007/s11695-009-0040-3

19. Gorodner V, Buxhoeveden R, Clemente G, Solé L, Caro L, Grigaites A (2015) Does laparoscopic sleeve gastrectomy have any influence on gastroesophageal reflux disease? Prelim Results Surg Endosc 29:1760-1768. https://doi.org/10.1007/s00464-014$3902-2$

20. Valezi AC, Herbella FA, Mali-Junior J, Menezes M de A, Liberatti M, Sato RO. (2017) Preoperative manometry for the selection of obese people candidate to sleeve gastrectomy. Arq Bras Cir Dig 30: 222-224. https://doi.org/10.1590/0102-6720201700030013

21. Ruiz de Angulo D, Jimeno Griño P, Ortiz Escandell MÁ, Munitiz Ruiz V, Gil Vázquez PJ, Pérez Flores D, Martínez de Haro LF, Miguel Hernández A, Parrilla Paricio P (2019) Evolution of gastroesophageal reflux after laparoscopic vertical gastrectomy. A radiographic, manometric and $\mathrm{pH}$-metric study. Rev Esp Enferm Dig 111:662-666. https://doi.org/10.17235/reed.2019.5972/2018

22. Sioka E, Tzovaras G, Tsiopoulos F, Papamargaritis D, Potamianos S, Chatzitheofilou C, Zacharoulis D (2017) Esophageal motility after laparoscopic sleeve gastrectomy. Clin Exp Gastroenterol 10: 187-194. https://doi.org/10.2147/CEG.S128631

23. Rebecchi F, Allaix ME, Giaccone C, Ugliono E, Scozzari G, Morino M (2014) Gastroesophageal reflux disease and laparoscopic sleeve gastrectomy: a physiopathologic evaluation. Ann Surg 260:909-915. https://doi.org/10.1097/SLA.0000000000000967

24. Kleidi E, Theodorou D, Albanopoulos K, Menenakos E, Karvelis MA, Papailiou J, Stamou K, Zografos G, Katsaragakis S, Leandros E (2013) The effect of laparoscopic sleeve gastrectomy on the antireflux mechanism: can it be minimized? Surg Endosc 27: 4625-4630. https://doi.org/10.1007/s00464-013-3083-4

25. Gemici E, Kones O, Seyit H, Surek A, Cikot M, Bozkurt MA, Alis $\mathrm{H}$ (2020) Outcomes of laparoscopic sleeve gastrectomy by means of esophageal manometry and $\mathrm{pH}$-metry, before and after surgery. Wideochirurgia I Inne Tech Maloinwazyjne 15:129-135. https:// doi.org/10.5114/wiitm.2019.83198

26. Coupaye M, Gorbatchef C, Calabrese D, Sami O, Msika S, Coffin B, Ledoux S (2018) Gastroesophageal reflux after sleeve gastrectomy: a prospective mechanistic study. Obes Surg 28:838-845. https://doi.org/10.1007/s11695-017-2942-9

27. Del Genio G, Tolone S, Limongelli P, Brusciano L, D’Alessandro A, Docimo G, Rossetti G, Silecchia G, Iannelli A, Del Genio A, Del Genio F, Docimo L (2014) Sleeve gastrectomy and development of "de novo" gastroesophageal reflux. Obes Surg 24:71-77. https:// doi.org/10.1007/s11695-013-1046-4

28. Tolone S, Savarino E, de Bortoli N, Frazzoni M, Frazzoni L, Savarino V, Docimo L (2020) Esophageal high-resolution manometry can unravel the mechanisms by which different bariatric techniques produce different reflux exposures. J Gastrointest Surg 24(1):1-7. https://doi.org/10.1007/s11605-019-04406-7

29. Burgerhart JS, Schotborgh CAI, Schoon EJ, Smulders JF, Van De Meeberg PC, Siersema PD, Smout AJPM (2014) Effect of sleeve gastrectomy on gastroesophageal reflux. Obes Surg 24:1436-1441. https://doi.org/10.1007/s11695-014-1222-1

30. Georgia D, Stamatina T, Maria N, Konstantinos A, Konstantinos F, Emmanouil L, Georgios Z, Dimitrios T (2017) 24-h Multichannel Intraluminal Impedance PH-metry 1 Year After Laparocopic Sleeve Gastrectomy: an objective assessment of gastroesophageal reflux disease. Obes Surg 27:749-753. https://doi.org/10.1007/ s11695-016-2359-x

31. Świdnicka-Siergiejko AK, Wróblewski E, Hady HR, Łuba M, Dadan J, Dąbrowski A (2018) Esophageal pH and impedance 
reflux parameters in relation to body mass index, obesity-related hormones, and bariatric procedures. Polish Arch Intern Med 128: 594-603. https://doi.org/10.20452/pamw.4334

32. Thereaux J, Barsamian C, Bretault M, Dusaussoy H, Lamarque D, Bouillot JL, Czernichow S, Carette C (2016) PH monitoring of gastro-oesophageal reflux before and after laparoscopic sleeve gastrectomy. Br J Surg 103:399-406. https://doi.org/10.1002/bjs. 10089

33. Yormaz S, Yilmaz H, Ece I, Y1lmaz F, Sahin M (2017) Midterm clinical outcomes of antrum resection margin at laparoscopic sleeve gastrectomy for morbid obesity. Obes Surg 27:910-916. https://doi. org/10.1007/s11695-016-2384-9

34. Patti MG, Diener U, Tamburini A, Molena D, Way LW (2001) Role of esophageal function tests in diagnosis of gastroesophageal reflux disease. Dig Dis Sci 46(3):597-602

35. Gyawali CP, Roman S, Bredenoord AJ, Fox M, Keller J, Pandolfino JE, Sifrim D, Tatum R, Yadlapati R, Savarino E; International GERD Consensus Working Group. (2017). Classification of esophageal motor findings in gastro-esophageal reflux disease: Conclusions from an international consensus group. Neurogastroenterol Motil. 2017 29(12). doi: https://doi.org/10. 1111/nmo.13104.

36. Savarino E, Gemignani L, Pohl D, Zentilin P, Dulbecco P, Assandri L, Marabotto E, Bonfanti D, Inferrera S, Fazio V, Malesci A, Tutuian R, Savarino V (2011) Oesophageal motility and bolus transit abnormalities increase in parallel with the severity of gastrooesophageal reflux disease. Aliment Pharmacol Ther 34(4):476486. https://doi.org/10.1111/j.1365-2036.2011.04742.x

37. Martinucci I, de Bortoli N, Giacchino M, Bodini G, Marabotto E, Marchi S, Savarino V, Savarino E (2014) Esophageal motility abnormalities in gastroesophageal reflux disease. World J Gastrointest Pharmacol Ther 5(2):86-96. https://doi.org/10.4292/wjgpt.v5.i2.86

38. Gyawali CP, Kahrilas PJ, Savarino E, Zerbib F, Mion F, Smout AJPM, Vaezi M, Sifrim D, Fox MR, Vela MF, Tutuian R, Tack J, Bredenoord AJ, Pandolfino J, Roman S (2018) Modern diagnosis of GERD: the Lyon Consensus. Gut 67(7):1351-1362. https://doi. org/10.1136/gutjnl-2017-314722

39. Oor JE, Roks DJ, Ünlü Ç, Hazebroek EJ (2016) Laparoscopic sleeve gastrectomy and gastroesophageal reflux disease: a systematic review and meta-analysis. Am J Surg Jan 211(1):250-267. https://doi.org/10.1016/j.amjsurg.2015.05.031

40. Peterli R, Wölnerhanssen BK, Peters T, Vetter D, Kröll D, Borbély Y, Schultes B, Beglinger C, Drewe J, Schiesser M, Nett P, Bueter M (2018) Effect of laparoscopic sleeve gastrectomy vs laparoscopic Roux-en-Y gastric bypass on weight loss in patients with morbid obesity: the SM-BOSS randomized clinical trial. JAMA 319(3): 255-265. https://doi.org/10.1001/jama.2017.20897

41. Kahrilas PJ, Bredenoord AJ, Fox M, Gyawali CP, Roman S, Smout AJ, Pandolfino JE, International High Resolution Manometry Working Group (2015) The Chicago Classification of esophageal motility disorders, v3.0. Neurogastroenterol Motil 27(2):160-174. https://doi.org/10.1111/nmo.12477

42. Rengarajan A, Bolkhir A, Gor P, Wang D, Munigala S, Gyawali CP (2018) Esophagogastric junction and esophageal body contraction metrics on high-resolution manometry predict esophageal acid burden. Neurogastroenterol Motil 30(5):e13267. https://doi.org/10. 1111/nmo.13267

43. Balko RA, Codipilly DC, Ravi K (2020) Minor esophageal functional disorders: are they relevant? Curr Treat Options Gastroenterol. https://doi.org/10.1007/s11938-020-00279-x

44. Shetler KP, Bikhtii S, Triadafilopoulos G (2017) Ineffective esophageal motility: clinical, manometric, and outcome characteristics in patients with and without abnormal esophageal acid exposure. Dis Esophagus 30(6):1-8. https://doi.org/10.1093/dote/dox012

45. Reddy CA, Baker JR, Lau J, Chen JW (2019) High-resolution manometry diagnosis of ineffective esophageal motility is associated with higher reflux burden. Dig Dis Sci 64(8):2199-2205. https://doi.org/10.1007/s10620-019-05633-3

46. Ho SC, Chang CS, Wu CY, Chen GH (2002) Ineffective esophageal motility is a primary motility disorder in gastroesophageal reflux disease. Dig Dis Sci 47(3):652-656. https://doi.org/10. 1023/a:1017992808762

47. Reddy CA, Patel A, Gyawali CP. (2017). Impact of symptom burden and health-related quality of life (HRQOL) on esophageal motor diagnoses. Neurogastroenterol Motil 29(4). https://doi.org/10. 1111/nmo.12970.

48. Jiang L, Ye B, Wang Y, Wang M, Lin L (2017) Esophageal body motility for clinical assessment in patients with refractory gastroesophageal reflux symptoms. J Neurogastroenterol Motil 23(1):64 71. https://doi.org/10.5056/jnm16047

49. Tolone S, De Bortoli N, Marabotto E, de Cassan C, Bodini G, Roman S, Furnari M, Savarino V, Docimo L, Savarino E (2015) Esophagogastric junction contractility for clinical assessment in patients with GERD: a real added value? Neurogastroenterol Motil 27(10):1423-1431. https://doi.org/10.1111/nmo.12638

50. Gor P, Li Y, Munigala S, Patel A, Bolkhir A, Gyawali CP (2016) Interrogation of esophagogastric junction barrier function using the esophagogastric junction contractile integral: an observational cohort study. Dis Esophagus 29(7):820-828. https://doi.org/10.1111/ dote. 12389

51. Lin S, Li H, Fang X (2019) Esophageal motor dysfunctions in gastroesophageal reflux disease and therapeutic perspectives. J Neurogastroenterol Motil 25(4):499-507. https://doi.org/10.5056/ jnm19081

52. Pandolfino JE, Kim H, Ghosh SK, Clarke JO, Zhang Q, Kahrilas PJ (2007) High-resolution manometry of the EGJ: an analysis of crural diaphragm function in GERD. Am J Gastroenterol 102(5):10561063. https://doi.org/10.1111/j.1572-0241.2007.01138.x

53. Zentilin P, Conio M, Mele MR, Mansi C, Pandolfo N, Dulbecco P, Gambaro C, Tessieri L, Iiritano E, Bilardi C, Biagini R, Vigneri S, Savarino V (2002) Comparison of the main oesophageal pathophysiological characteristics between short- and long-segment Barrett's oesophagus. Aliment Pharmacol Ther 16(5):893-898. https://doi.org/10.1046/j.1365-2036.2002.01237.x

54. Chan WW, Haroian LR, Gyawali CP (2011) Value of preoperative esophageal function studies before laparoscopic antireflux surgery. Surg Endosc 25(9):2943-2949. https://doi.org/10.1007/s00464011-1646-9

55. Mechanick JI, Youdim A, Jones DB, Garvey WT, Hurley DL, McMahon MM, Heinberg LJ, Kushner R, Adams TD, Shikora S, Dixon JB, Brethauer S, American Association of Clinical Endocrinologists; Obesity Society; American Society for Metabolic \& Bariatric Surgery (2013) Clinical practice guidelines for the perioperative nutritional, metabolic, and nonsurgical support of the bariatric surgery patient-2013 update: cosponsored by American Association of Clinical Endocrinologists, The Obesity Society, and American Society for Metabolic \& Bariatric Surgery. Obesity (Silver Spring) 21(Suppl 1):S1-S27. https://doi.org/10. 1002/oby.20461

56. Di Lorenzo N, Antoniou SA, Batterham RL, Busetto L, Godoroja D, Iossa A, Carrano FM, Agresta F, Alarçon I, Azran C, Bouvy N, Balaguè Ponz C, Buza M, Copaescu C, De Luca M, Dicker D, Di Vincenzo A, Felsenreich DM, Francis NK, Fried M, Gonzalo Prats B, Goitein D, Halford JCG, Herlesova J, Kalogridaki M, Ket H, Morales-Conde S, Piatto G, Prager G, Pruijssers S, Pucci A, 
Rayman S, Romano E, Sanchez-Cordero S, Vilallonga R, Silecchia G (2020) Clinical practice guidelines of the European Association for Endoscopic Surgery (EAES) on bariatric surgery: update 2020 endorsed by IFSO-EC, EASO and ESPCOP. Surg Endosc 34(6): 2332-2358. https://doi.org/10.1007/s00464-020-07555-y

57. Carabotti M, Avallone M, Cereatti F, Paganini A, Greco F, Scirocco A, Severi C, Silecchia G (2016) Usefulness of upper gastrointestinal symptoms as a driver to prescribe gastroscopy in obese patients candidate to bariatric surgery. A Prospective Study. Obes Surg 26(5):1075-1080. https://doi.org/10.1007/s11695-015-1861$\mathrm{x}$

58. Fried M, Yumuk V, Oppert JM, Scopinaro N, Torres AJ, Weiner R, Yashkov Y, Frühbeck G, European Association for the Study of Obesity; International Federation for the surgery of obesity European Chapter (2013) Interdisciplinary European guidelines on metabolic and bariatric surgery. Obes Facts 6(5):449-468. https://doi.org/10.1159/000355480
59. Savarino E, Bredenoord AJ, Fox M, Pandolfino JE, Roman S, Gyawali CP, International Working group for disorders of gastrointestinal motility and function (2018) Advances in the physiological assessment and diagnosis of GERD. Nat Rev Gastroenterol Hepatol 15(5):323. https://doi.org/10.1038/nrgastro.2018.32

60. Pallati PK, Shaligram A, Shostrom VK, Oleynikov D, McBride CL, Goede MR (2014) Improvement in gastroesophageal reflux disease symptoms after various bariatric procedures: review of the bariatric outcomes longitudinal database. Surg Obes Relat Dis 10(3):502507. https://doi.org/10.1016/j.soard.2013.07.018

61. Chuffart E, Sodji M, Dalmay F, Iannelli A, Mathonnet M (2017) Long-term results after sleeve gastrectomy for gastroesophageal reflux disease: a single-center french study. Obes Surg 27(11): 2890-2897. https://doi.org/10.1007/s11695-017-2698-2

Publisher's note Springer Nature remains neutral with regard to jurisdictional claims in published maps and institutional affiliations. 